\title{
INGRESSO NO SERVIÇO PÚBLICO BANCÁRIO NO BRASIL: CUMPRIMENTO CONSTITUCIONAL?
}

\section{ADMISSION TO BANKING PUBLIC SERVICE IN BRAZIL: CONSTITUTIONAL COMPLIANCE?}

\author{
${ }^{1}$ Raquel Maria Azevedo Pereira Farias \\ ${ }^{2}$ Giovanna Paola Batista de Britto Lyra Moura
}

\section{RESUMO}

No que pertine às instituições bancárias públicas, concursos são realizados, mas o cadastro de reserva deixa os classificados na expectativa de serem chamados, o que pode não acontecer. Outro instituto que compromete o ingresso do concursado é a terceirização, formalmente constituída, mas cuja finalidade é contratar mão-de-obra barata e especializada em detrimento do alto custo do servidor público. O crescimento econômico, a globalização e o mercado informal aumentam os lucros bancários às custas de pessoas que dedicam suas vidas à aprovação em concurso, enquanto há aquelas que esperam uma oportunidade e se submetem à precarização por meio da terceirização.

Palavras-chave: Serviço público, Concurso, Instituição bancária, Terceirização

\begin{abstract}
Concerning public banking institutions, many tenders take place, however "reservation register" retain people in the expectation of being hired, which may not happen. Another institute that compromises the hiring of those is the outsourcing process that is formally constituted, but whose aim is the hiring of cheap and skilled labor not to shoulder the high costs of a public worker. Economic growth, globalization, the informal market, increase banks' profits at the expenses of people who dedicate their lives to succeed in a public tender while there are those who submit themselves to the precarious work conditions of the outsourcing.
\end{abstract}

Keywords: Public service, Tender, Banking institution, Outsourcing

\footnotetext{
${ }^{1}$ Mestranda pelo Programa de Pós-Graduação em Direito pelo Centro Universitário de João Pessoa - UNIPÊ, Paraíba (Brasil). Professora da Associação Paraibana de Ensino Renovado - ASPER, Paraíba (Brasil). E-mail: raquelmazevedo@yahoo.com.br

${ }^{2}$ Mestre em Direito e Desenvolvimento Sustentável pelo Centro Universitário de João Pessoa - UNIPÊ, Paraíba (Brasil). Professora da Associação Paraibana de Ensino Renovado - ASPER, Paraíba (Brasil). E-mail: giovannalyra@hotmail.com
} 


\section{INTRODUÇÃO}

É cediço que o ingresso no serviço público se dá por meio do concurso público, tal obrigação decorrendo do dispositivo constitucional contido do art. 37, que impõe tal medida. O mesmo se aplica às Instituições Bancárias Públicas do Brasil, a exemplo da CEF - Caixa Econômica Federal, o BNB - Banco do Nordeste do Brasil S/A e BB - Banco do Brasil S/A. Estas instituições, ainda que gozem de regimes jurídicos distintos, devem obediência ao artigo retromencionado, sendo que apenas o indivíduo aprovado em concurso público e que toma posse na CEF se torna servidor público estatutário.

Todavia, durante anos, os concursos públicos, de uma forma geral, foram realizados majoritariamente para cadastro de reserva, ou seja, os candidatos classificados ficavam à mercê da discricionariedade do órgão público para convocação até o término do prazo prescricional do certame, gerando apenas uma mera expectativa de direito, fazendo como que, por vezes, o candidato fosse aprovado no concurso e não viesse a ser convocado por desinteresse da Administração Pública. Tal prática vem sendo repudiada pelos Tribunais e combatida pelo Ministério Público, por meio das Ações Civis Públicas.

A partir do século XX, a vida econômica foi sendo regida pelo modo de produção capitalista, que trouxe consigo uma série de conflitos econômicos e sociais. A crise da modernidade liberal gerou um período de desemprego avassalador, fazendo com que a economia gritasse por novos rumos. As ideias kenesyanas e o modo de produção fordista foram utilizados na tentativa de gerar emprego e fazer a economia crescer.

Em apertada síntese, as ideias Kenesyanas impunham maior intervenção possível do Estado na economia, seja nas empresas públicas ou privadas, sendo contrárias ao liberalismo econômico.

Quanto ao modo de produção fordista, criado por Henry Ford, este tinha como finalidade acrescer à produção através do aumento de eficiência e baixar o preço do produto, resultando no aumento das vendas que, por sua vez, permitiria manter baixo o preço do produto.

Considerando que a principal vantagem competitiva residia na produção de baixo custo (e não na variedade), todo o sistema produtivo foi projetado para produzir num fluxo ininterrupto.

A partir deste modo de produção, surgiu a terceirização, que consiste em uma prática de mercado em que a empresa se concentra na sua atividade principal, chamada de atividadefim e terceiriza, ou seja, contrata uma outra empresa, denominada prestadora de serviço, para 
a realização das atividades que não fazem parte do núcleo da empresa tomadora, chamada de atividade-meio, criando uma relação trilateral entre tomador do serviço, contratado e prestador do serviço.

Pode-se dizer, ainda, que se está diante de uma técnica, segundo a qual a empresa tomadora do serviço descentraliza suas atividades, atribuindo à empresa terceirizante a execução de tarefas secundárias, concentrando-se, assim, em suas atividades primordiais e, por conseguinte, garantindo um serviço cada vez mais especializado.

Por volta de 1950, o Brasil passou a adotar o sistema de terceirização, com o fito de enxugar a mão-de-obra, aumentar a produção e, por conseguinte, otimizar os custos e alcançar maior lucratividade. Este sistema passou a ser igualmente implementado nas instituições bancárias, em sua maioria das vezes, de forma precária, com o intuito de burlar as súmulas existentes e o entendimento dos nossos Tribunais acerca da sua utilização, impedindo, assim, a contratação de novos servidores públicos, ainda que celetistas.

Nesse cenário, será analisado, de forma específica, o processo de seleção realizado pelo Banco do Brasil S/A, seleção externa 2012/003, Edital nº 3 - 2012/003, de 19.10.2012 e o Edital de seleção externa 2014/002, edital $n^{\circ} 2$, de 18.12.2014 e suas relações com os Editais de licitação de 2012 e 2013.

Destarte, duas dimensões serão trabalhadas neste artigo, com o intuito de analisar a dificuldade de efetivação de servidores públicos nas instituições bancárias do Brasil, quais sejam, a abertura de concurso público para cadastro de reserva de forma contínua e as licitações para empregados terceirizados sem comprovação do embasamento legal para justificar tal contratação.

Frise-se que a análise de dados foi limitada à região Nordeste do Brasil, sendo estes extraídos do site da própria instituição financeira. A partir da análise destes dados, serão demonstradas as possíveis consequências que tais dimensões podem ocasionar àqueles que almejam não mais a aprovação, mas a nomeação em um concurso público na esfera bancária.

Salutar, por fim, registrar que estas dimensões foram eleitas para delimitação do trabalho, inobstante existirem outros fatores que possam contribuir ou não para ineficácia do dispositivo constitucional. No que pertine ao edital de seleção, a escolha se deu em razão da repercussão dada ao referido concurso, vez que este foi objeto de inúmeras ações coletivas e individuais, inclusive de iniciativa do próprio Ministério Público do Trabalho do Distrito Federal - DF (Processo $n^{\circ}$ 0000267.-83.2015.5.10.0020), que requereu a prorrogação do prazo prescricional em razão do Banco do Brasil ter aberto três editais consecutivos para 
cadastro de reserva e com cargos idênticos, concurso este, frise-se, em nível nacional, daí tamanha repercussão.

\section{CONCURSO PÚBLICO E O CADASTRO DE RESERVA}

Conforme mencionado o Concurso Público possui sustentação constitucional, pelo que deve ser obedecido por todas as entidades da administração direta e indireta.

Nesse sentindo, o inciso II do art. 37 da Constituição Federal garante que a investidura em cargo ou função pública depende de aprovação prévia em concurso público, salvo devidas exceções, in verbis:

\footnotetext{
“Art. 37. A administração pública direta e indireta de qualquer dos Poderes da União, dos Estados, do Distrito Federal e dos Municípios obedecerá aos princípios de legalidade, impessoalidade, moralidade, publicidade e eficiência e, também, ao seguinte:

(...)

II - a investidura em cargo ou emprego público depende de aprovação prévia em concurso público de provas ou de provas e títulos, de acordo com a natureza e a complexidade do cargo ou emprego, na forma prevista em lei, ressalvadas as nomeações para cargo em comissão declarado em lei de livre nomeação e exoneração;"
}

É sabido que, quando um concurso é lançado sem que seja definido o número de vagas, ao candidato classificado resta apenas a expectativa de direito, sendo, pois, classificados apenas aqueles que, tendo sido aprovados, estão, por força da pontuação obtida, dentro do número de vagas imposto pela Administração Pública.

Desse modo, enquanto o candidato encontra-se no cadastro reserva, o que surge para ele é uma mera expectativa de seu direito à nomeação. Entretanto, surgindo nova vaga durante o prazo de validade do certame público, a Administração Pública fica vinculada à convocação do candidato da vaga subsequente.

De outro norte, sabe-se que a convocação dos aprovados no concurso público é realizada de forma discricionária pela Administração Pública, que irá analisar a previsão orçamentária e necessidade de pessoal, sempre, é claro, observando as vagas disponibilizadas e o prazo de validade do concurso para os cadastros de reserva.

No entanto, essa sistemática é remodelada quando a Administração Pública, de algum modo, manifesta, de maneira inequívoca e objetiva, a necessidade, a conveniência e a intenção de provimento do mesmo cargo, no prazo de validade do concurso público. 
Nessa ocasião, a mera expectativa se convola em legítimo direito subjetivo do candidato a ser nomeado para o cargo a que concorreu e foi aprovado.

Ora, essa observância pela Administração ao texto legal é imposição decorrente do princípio constitucional da legalidade administrativa e da própria natureza de Estado de Direito da República Federativa do Brasil.

Acerca do tema, eis a doutrina do consagrado Luciano Ferraz (2014):

\begin{abstract}
“(...) a aprovação no concurso público não gera mera simples expectativa de direitos de ser nomeado ao aprovado, gera-lhe direito subjetivo presumido à nomeação. Com efeito, se a Administração deixar transparecer, seja na publicação do Edital, seja mediante a prática de atos configuradores de desvio de poder (contratações temporárias e terceirizações de serviço), que necessita de mão-de-obra dos aprovados, ou ainda se surgiram novas vagas durante o prazo de validade do concurso, a expectativa se transmuda em direito subjetivo. Vislumbra-se (...) que os aprovados no concurso possuem direito subjetivo presumido à nomeação e à prorrogação do prazo de validade, inteligência que na prática, transfere à Administração Pública o ônus de demonstrar, com argumentos razoavelmente aceitáveis (v.g. excesso de despesas de pessoal), os motivos que ensejaram a nãoadoção dessas medidas."
\end{abstract}

Ora, o STJ já se manifestou no sentido de que ignorar o cadastro de reserva fere os princípios que devem nortear o acesso ao serviço público, que se pautam pelo mérito comprovado, de forma que os atos praticados pela reclamada só lhe imputam o dever de convocação do reclamante.

Todavia, a situação se agrava ainda mais quando a Administração Pública abre um certame para cadastro de reserva, os candidatos são classificados e ficam na expectativa de serem convocados enquanto perdurar o prazo prescricional estabelecido pela própria administração, porém a surpresa ou frustração, melhor dizendo, acontece quando, no curso deste prazo, no caso aqui trabalhado, o Banco abre um novo concurso para as mesmas vagas.

No caso do concurso do Edital 2012/003, Edital n o 3 - 2012/003, de 19.10.2012, objeto de análise desse trabalho, este teve o prazo prescricional fixado pelo Banco do Brasil para abril/2015, porém, em 18 de dezembro de 2014, referida instituição publicou um novo edital para seleção externa 2014/002, Edital n 02, com as mesmas convocações, o que levou os candidatos, em nível nacional, a ingressarem com inúmeras ações judiciais requerendo o direito à convocação já que a instituição, ao abrir novo certame, atestou a necessidade do serviço e a existência de vagas e, portanto, deveria contratar os já aprovados.

Em que pese as peculiaridades deste edital, reitera-se que este trabalho se limitará à análise do referido na perspectiva do cadastro de reserva e da terceirização dos candidatos da região do Nordeste. 


\subsection{Análise Dos Editais 2012/003 e 2014/002 - Cadastro De Reserva}

À luz do que fora tratado até o presente, a Tabela 1 mostra o número de candidatos classificados, repita-se, conforme reflete o edital, bem como quantos foram efetivamente convocados, já que tal certame fora aberto para cadastro de reserva, ou seja, os candidatos aprovados estariam diante de uma mera expectativa de direito, submissos à discricionariedade da administração pública, no caso, o Banco do Brasil S/A.

Salutar reforçar que o quantitativo informado no gráfico abaixo não distingue os candidatos que foram convocados voluntariamente pelo Banco do Brasil S/A daqueles que foram convocados por ordem judicial decorrentes de ações judiciais individuais ou coletivas, por ser, irrelevante para este estudo a natureza da nomeação, já que a intenção é verificar se a abertura de certame para concurso público nas instituições bancárias públicas no Brasil pode comprometer o direito constitucional do cidadão ao ingresso nos cargos ou empregos públicos por utilização excessiva do cadastro de reserva.

Tabela 1 - Número de candidatos, por estado, classificados e convocados no concurso para o Banco do Brasil lançado através do Edital 2012/3 em 19/10/2012.

\begin{tabular}{|c|c|c|}
\hline Estado & $\begin{array}{c}\text { Classificados } \\
\text { (Inclusos os Deficientes) }\end{array}$ & $\begin{array}{c}\text { Convocados } \\
\text { (Inclusos os Deficientes) }\end{array}$ \\
\hline Ceará & 966 & 244 \\
\hline Paraíba & 525 & 116 \\
\hline Pernambuco & 630 & 277 \\
\hline Rio Grande do Norte & 315 & 132 \\
\hline Maranhão & 473 & 282 \\
\hline Piaui & 420 & 83 \\
\hline Sergipe & 210 & 58 \\
\hline TOTAL & 3.539 & 1.192 \\
\hline
\end{tabular}

Pois bem, a par dessas informações, tem-se que do Concurso Público realizado pelo Banco do Brasil S/A (edital 2012/3) para cadastro de reserva, foram classificados 3.539 (três mil quinhentos e trinta e nove) candidatos, incluindo os deficientes. Destes, foram efetivamente convocados 1.129 (hum mil cento e vinte e nove) classificados, uma média de $32 \%$ (por cento) dos classificados que teriam até o mês de abril de 2015 para serem convocados.

Em determinadas regiões, como Paraíba e Sergipe, o percentual ficou bastante aquém desta média, porquanto menos de $20 \%$ dos classificados foram convocados, mas os restantes 
ainda continuavam nesta expectativa, já que o concurso para o qual se submeteram ainda estaria dentro do prazo prescricional.

Todavia, em razão do cadastro de reserva refletir uma mera expectativa de direito, o Banco do Brasil S/A, valendo-se dessa máxima, conforme já esposado, publicou novo edital em 18 de dezembro de 2014 para seleção externa 2014/002, Edital n ${ }^{\circ}$ 02, igualmente para cadastro de reserva, ainda na vigência do anterior (Tabela 2).

Tabela 2 - Número de candidatos, por Estado, classificados e convocados no concurso para o Banco do Brasil lançado através do Edital 2014/2 em 18/12/2014.

\begin{tabular}{|c|c|c|}
\hline Estado & $\begin{array}{c}\text { Classificados } \\
\text { (Inclusos os Deficientes) }\end{array}$ & $\begin{array}{c}\text { Convocados } \\
\text { (Inclusos os Deficientes) }\end{array}$ \\
\hline Ceará & 142 & 45 \\
\hline Paraíba & 80 & 7 \\
\hline Pernambuco & 160 & 33 \\
\hline Rio Grande do Norte & 81 & 40 \\
\hline Maranhão & 170 & 51 \\
\hline Piaui & 60 & 12 \\
\hline Sergipe & 40 & 3 \\
\hline TOTAL & 733 & 191 \\
\hline
\end{tabular}

Note-se que, ao analisar os quadros acima, constata-se que, em razão da ausência de norma expressa que impeça a abertura de certame para cadastro de reserva, o Banco do Brasil S/A, na vigência do anterior, lançou novo edital e, à guisa de informação continua lançando editais consecutivos, na vigência de editais anteriores para cadastro de reserva, fazendo precluir a expectativa dos candidatos de serem convocados para o labor na instituição financeira.

Perceba-se, ainda, que, em cada certame aberto, um quantitativo de candidatos são classificados - no caso do primeiro edital, foram classificados 3.539 (três mil quinhentos e trinta e nove) candidatos, incluindo os deficientes, porém foram efetivamente convocados 1.129 (hum mil cento e vinte e nove) classificados, uma média de 32\% (por cento) dos classificados, ou seja, 2.410 (dois mil quatrocentos e dez) candidatos classificados não foram convocados para assumir o cargo público e, ainda na vigência do seu edital, ainda na expectativa do seu direito, o Banco abre um novo certame para os mesmos cargos, nas mesmas regiões, igualmente para cadastro de reserva. 
Pois bem. Ainda que restando mais de 2.000 (dois mil) candidatos classificados, e repita-se, na vigência do prazo prescricional, a instituição financeira lançou novo edital e classificou 733 (setecentos e trinta e três candidatos) e convocou 191 (cento e noventa e um), o que leva a conclusão, a partir de um simples cálculo aritmético que, no primeiro edital, as vagas poderiam ter sido preenchidas e ainda sobrariam candidatos classificados, dispensando a necessidade de novo certame.

Salutar, ainda, verificar que, no novo concurso - Edital 2014/02 -, também é possível destacar o percentual mínimo de convocação, ainda que, frise-se, referido edital esteja dentro do prazo prescricional. Pode-se citar a regiões como Sergipe e Paraíba onde não se alcançou sequer o percentual de $10 \%$ dos candidatos classificados e convocados.

Sendo assim, na perspectiva do uso do cadastro de reserva, é possível perceber que a instituição financeira aqui estudada tem comprometido o ingresso dos candidatos ao serviço público, mesmo tendo eles se submetido ao concurso público, infringindo a norma constitucional que garante ao cidadão o acesso a tais cargos.

\section{TERCEIRIZAÇÃO}

No Brasil, a terceirização foi introduzida pela indústria multinacional, principalmente a automobilística, que, no final da década de 1950, contratou serviços de terceiros para produzirem os componentes do automóvel, deixando para a indústria apenas a montagem.

Desta forma, a produção se desenvolvia de forma cada vez mais rápida, os custos tornavam-se menores e a empresa poderia focar no desenvolvimento do seu produto e em sua venda.

Não havia, ainda, na maioria dos casos, uma preocupação em utilizar a técnica para obter ganhos de qualidade e produtividade.

As empresas prestadoras de serviço, por sua vez, não se preocupavam em melhorar seus serviços, vez que a ideia básica consistia em manter seus empregados nas instalações das empresas contratantes, sem estabelecer uma política de aperfeiçoamento desses profissionais.

Com o mercado em rápida expansão, com baixo custo de produção e consumidores menos preocupados com a qualidade, reinava um clima próspero e otimista.

Doutro norte, o crescimento do número de empresas pelo mundo todo foi o marco para o início de uma concorrência acirrada, vez que os meios de comunicação evoluíam rapidamente, bombardeando os consumidores com informações diárias, fazendo com que 
estes adotassem novos comportamentos, questionando cada produto antes de adquiri-los, na busca de uma melhor qualidade e menor preço.

Nesse período, as empresas passaram a identificar as áreas de interesse estratégico, ou seja, a atividade-fim da empresa, e, consequentemente, a terceirizar as atividades-meio, gradativamente.

A prática da terceirização como técnica de mercado de redução de custo e otimização do trabalho vem alcançando repercussões muito negativas nas relações laborais quando mal empregada, vez que tem aviltado os direitos sociais do trabalho garantidos pela Carta Magna.

A terceirização, consoante informa Catharino (2005, p. 19):

\footnotetext{
“(...) é a forma de organização estrutural que permite a uma empresa transferir a outra suas atividades-meio, proporcionando maior disponibilidade de recursos para sua atividade-fim, reduzindo a estrutura operacional, diminuindo os custos, economizando recursos e desburocratizando a administração."
}

De igual modo esse aviltamento repercute também na esfera administrativa, vez que os candidatos aprovados em concurso público, seja dentro do número de vagas, seja para cadastro de reserva, tem sido preteridos em detrimento da contratação de empresa interposta, sob o manto de uma suposta legalidade (contratos licitatórios).

Essa preterição, tal como a aprovação dentro do número de vagas previstas no edital, transmuta a "expectativa em direito" dos candidatos a verdadeiro direito subjetivo. Isto porque, a partir da demonstração da necessidade de provimento pela Administração de um determinado número de vagas, a nomeação e a posse, que seriam, a princípio discricionárias, tornam-se verdadeiros atos vinculados, gerando, em contrapartida, direito subjetivo para o candidato aprovado dentro de tal previsão.

De outro norte, à guisa de esclarecimento, não se pode confundir discricionariedade com desvio de poder, vez que, quando a Administração opta em contratar terceirizados ou se utilizar de qualquer outra forma de gestão para preterir concursados classificados no certame, esta incide em desvio de poder e não manifestação legítima de vontade, pois aquele se dá quando há a violação do interesse público consubstanciado no atentado à finalidade ou objeto do concurso, que é o preenchimento das vagas.

Em sendo as instituições bancárias uma das modalidades das instituições financeiras, convém ressaltar que aqueles que desempenham suas funções dentro de bancos, ou seja, os bancários, gozam de tratamento especial previsto nos art. 224, 225 e 226 da CLT. 
A execução das suas atividades possui aspectos peculiares quanto à natureza e à responsabilidade, as quais os colocam como sujeito de um contrato especial de trabalho. A atenção constante no exercício das funções submete o empregado aos riscos da fadiga, autorizando a redução da jornada, razão pela qual se deve adotar todas as cautelas possíveis na contratação de serviços por trabalhador terceirizado.

Com o intuito de solucionar o problema, a legislação heterônoma incorporou um diploma normativo que tratava especificamente da terceirização, estendendo-a ao campo privado da economia: a Lei do Trabalho Temporário (Lei ${ }^{\circ}$ 6.019/74). Tempos depois, pela Lei $n^{\circ} 7.102 / 83$, autorizava-se também a terceirização do trabalho de vigilância bancária, a ser efetuado em caráter permanente, ao contrário da terceirização autorizada pela lei no 6.019 , que era temporária, de forma que só pode ser utilizada em casos excepcionais e com prazo previamente estipulado para início e fim.

Conforme leciona Delgado (2002, p. 434), as súmulas do TST - Tribunal Superior do Trabalho exerceram e exercem importante papel no controle civilizatório da Terceirização trabalhista no Brasil.

\footnotetext{
"Não obstante o pequeno grupo de normas autorizativas da terceirização, o processo acentuou-se no segmento privado da economia nas décadas seguintes a 1970 - em amplitude e proporção muito superior às hipóteses permissivas contidas nos diplomas acima mencionados. Tais circunstâncias induziram à realização de esforço hermenêutico destacado por parte dos Tribunais do Trabalho, na busca da compreensão da natureza do processo e, afinal, do encontro da ordem jurídica a ele aplicável com seus empregados."
}

Assim, Diniz (1999, p.20), mesmo apontando diversos malefícios decorrentes do processo, como a precarização do trabalho e do desemprego, afirma que:

\footnotetext{
“A terceirização como já explicitado, foi uma saída da classe empresarial à necessidade de barateamento da mão-de-obra; ao contrário do que pensam alguns, não deve ser simples, nem absolutamente proibida; é um sinal dos tempos e como tal deve o direito do trabalho compreendê-la e decifrar suas estruturas, a fim de poder encontrar soluções para a classe trabalhadora, a quem ele serve, dentro desse novo contexto socioeconômico."
}

Em que pese a existência de concurso público válido e a existência de pessoal aprovado e não convocado, o Banco do Brasil S/A tem mantido a contratação de pessoal terceirizado realizando as funções típicas de bancário/escriturário.

Salutar repisar que a terceirização só pode ser considerada lícita nos casos de serviços de vigilância e limpeza e outras atividades que não realizem a atividade-fim da empresa, de 
forma que em um contrato de licitação firmado pela Administração Pública só se concebe quando explicitar claramente quais os serviços a serem realizados pela empresa contratante.

Neste diapasão, convém diferenciar atividade-fim e atividade-meio de uma empresa, sendo a primeira aquela atividade nuclear da empresa, ou seja, a atividade principal, sem a qual ela não seria a empresa que é, enquanto a segunda congloba as atividades periféricas, que contribuem para o desenvolvimento da atividade principal.

Segundo Barros (2008, p. 33), por atividade-fim entenda-se aquela cujo objetivo a registra na classificação socioeconômica, destinado ao atendimento das necessidades socialmente sentidas.

\subsection{Análise Dos Editais De Licitação 2012/2013 - Banco Do Brasil S/A}

A segunda dimensão a ser analisada é se a terceirização utilizada pelas instituições bancárias públicas do Brasil, da maneira como vem sendo realizada, pode comprometer o ingresso do cidadão ao cargo ou função pública almejada.

Nesse contexto, para verificar tal premissa foi analisado o Edital de Licitação realizado pelo Banco do Brasil S/A de 2012 e 2013 (Tabela 3), para constatar se a terceirização seria para prestação de serviços de limpeza, de vigilância ou para atividade-meio da empresa, devendo o documento, conforme já mencionado, ser explícito e cristalino para não restar dúvida acerca da atividade a ser desempenhada.

Mais uma vez, basta um simples cálculo aritmético para verificar que quase $35 \%$ de funcionários terceirizados foram contratados sob o manto da Lei de Licitações, porém, violando a natureza jurídica da terceirização. Ademais, salutar informar que o primeiro Edital objeto deste estudo seria suficiente para suprir o quantitativo de terceirizados e os convocados até agora no segundo certame, o qual, repita-se, fora aberto na vigência de um anterior.

Para tanto, transcreve-se aqui o objeto do contrato licitatório objeto da análise:

\footnotetext{
“A - DO OBJETO DO CONTRATO - Terceirizados O Banco do Brasil realiza licitações para a contratação de empresas de terceirização. O Edital de Licitação (documento anexo) descreve que "o OBJETO da licitação é Contratação de empresa prestadora de serviços temporários para atender à necessidade transitória de mão-deobra, decorrente do acréscimo extraordinário, temporário e imprevisível de serviço".
} 
Tabela 3 - Quantitativo de terceirizados contratados pelo Banco do Brasil para realizações de serviços não explicitamente informados, bem como descaracterizado da natureza de temporário, em relação ao número de candidatos aprovados e classificados em concurso público.

\begin{tabular}{|l|c|}
\hline $\begin{array}{l}\text { Total de trabalhadores terceirizados } \\
\text { contratatos pelo Banco do Brasil no } \\
\text { nordeste no biênio 2012/2013 }\end{array}$ & 1.138 \\
\hline $\begin{array}{l}\text { Total de candidatos classificados no } \\
\text { concurso público - Edital 2012/3 } \\
\text { (nordeste) }\end{array}$ & 3.539 \\
\hline Total de convocados no nordeste & 1.192 \\
\hline
\end{tabular}

Veja que o edital descreve, de forma genérica, a necessidade do serviço a comprova, mas não especifica qual o serviço, pois o próprio objeto do contrato de prestação de serviço, por si só, já comprova a necessidade de pessoal e ausência do caráter temporário. Ora, se fosse o caso de necessidade transitória de mão-de-obra, decorrente de acréscimo extraordinário, temporário e imprevisível de serviço, tais contratos não estariam sendo renovados periodicamente e sucessivamente, ano após ano.

Destarte, descaracterizado está o caráter extraordinário e imprevisível de serviço, a justificar a contratação transitória e temporária de pessoal. O Banco manteve esses contratos pelo período de 2 anos, conforme o contrato licitatório extraído do Diário ISNN 1677-7069 Diário Oficial da União - Seção 3 nº 197, quarta-feira, 10 de outubro de 2012 e os renovou conforme ISNN 1677-7069 Diário Oficial da União - Seção $3 \mathrm{n}^{\circ}$ 146, quarta-feira, 31 de julho de 2013, de modo que é patente a má-fé da instituição em, ainda assim, promover concursos com cadastro de reserva, ao passo que, paralelamente, contrata pessoas para desempenharem funções típicas do concurso realizado e não convoca os aprovados.

Relevante, ainda, mencionar que, no que pertine às atividades propostas pelo edital do Concurso Público - SELEÇÃO EXTERNA 2012/003/EDITAL No 3 - 2012/003), o item 2.4 dispõe acerca das atividades a serem realizadas pelo ESCRITURÁRIO, quais sejam:

\footnotetext{
"Comercialização de produtos e serviços do Banco, atendimento ao público, atuação no caixa (quando necessário), contatos com clientes, prestação de informações aos clientes e usuários; redação de correspondências em geral; conferência de relatórios e documentos; controles estatísticos; atualização/manutenção de dados em sistemas operacionais informatizados; execução de outras tarefas inerentes ao conteúdo ocupacional do cargo, compatíveis com as peculiaridades do BANCO DO BRASIL S.A.”
}

No caso dos editais de contratação da empresa de trabalho temporário, não há descrição das atividades a ser realizadas pelos terceirizados. Na Cláusula 6.3.3, da seção de justificativas (6.3) do contrato, apenas há a seguinte previsão: 
“A utilização de mão-de-obra temporária para a realização de tarefas de apoio administrativo de menor complexidade, porém não menos importantes, permite direcionar a força de trabalho do quadro permanente para atividades que requeiram mão-de-obra já qualificada".

Por sua vez, o item 2 (Tarefas), assim preceitua:

\begin{abstract}
"Os serviços serão prestados nas dependências determinadas pelo Banco do Brasil e consistirão na execução e/ou auxílio de tarefas internas ou externas, complementares ou de apoio aos serviços administrativos, operação de máquinas ou aparelhos auxiliares de trabalhos burocráticos e auxílio em serviços de natureza manual ou mecânica, de acordo com as instruções fornecidas pelo Banco."
\end{abstract}

Nota-se, pois, que o item acima se refere a uma cláusula totalmente aberta, vez que não especifica o trabalho realizado. No entanto, na prática, a atividade realizada por estes empregados terceirizados é eminentemente bancária, pois envolve abertura de conta, análise de crédito, cadastros, etc.

Convém ainda mencionar que há vários processos que confirmam a tese aqui aventada, no que pertine à contratação de terceirizados, utilizando-se de uma legalidade formal, em detrimento da real, como é o caso dos processos $n^{\circ} 0082200-22.2013 .5 .13 .0002$ e n. 0087400-47.2013.513.0022 (TRT13).

Seguem algumas jurisprudências recentes, não só envolvendo a instituição bancária em comento, mas em defesa da moralidade do serviço público em geral:

"PRETERIÇÃO DE CANDIDATO APROVADO EM CONCURSO PÚBLICO REALIZADO PELO BANCO DO BRASIL PARA CADASTRO RESERVA. TERCEIRIZAÇÃO. EFEITOS. Preterido por força da contratação empresarial de trabalho terceirizado ou temporário de qualquer espécie, o candidato aprovado em concurso público promovido pelo Banco do Brasil para cadastro reserva faz jus a respectiva nomeação. Em tal cenário, uma mera expectativa transforma-se em direito efetivo do trabalhador aprovado em regular certame. Além de ilegal, a terceirização na atividade fim bancária levada a cabo por ente da administração pública ofende os princípios orientadores da administração pública, especialmente o da moralidade e o da impessoalidade, previstos no artigo 37, da Constituição Federal. Recurso do reclamante conhecido e parcialmente provido. (TRT da $10^{\mathrm{a}}$ Região - Proc. RO-0000538-23.2014.5.10.0022 - Primeira Turma - Rel. Des.

E ainda: Grijalbo Fernandes Coutinho - DEJTDF de 10.4.2015).”

“ADMINISTRATIVO. AGRAVO REGIMENTAL NO RECURSO ESPECIAL.
CONCURSO PÚBLICO. MÉDICO OFTALMOLOGISTA DA UNIVERSIDADE
FEDERAL FLUMINENSE. CONTRATAÇÃO TEMPORÁRIA DENTRO DO
PRAZO DE VALIDADE DO CONCURSO. COMPROVADA A PRETERIÇÃO
DO CANDIDATO APROVADO NO CERTAME. RECONHECIDO O DIREITO
À NOMEAÇÃO. NOVA QUALIFICAÇÃO JURÍDICA DOS FATOS
DELIMITADOS NO ARESTO RECORRIDO. NÃO INCIDENCIA DA SÚMULA
7/STJ. AGRAVO REGIMENTAL DESPROVIDO. 1. A manutenção de contratos
temporários para suprir a demanda por Médicos Oftalmologistas, demonstra a
necessidade premente de pessoal para o desempenho da atividade, revelando
flagrante preterição daqueles que, aprovados em concurso ainda válido, estariam 
aptos a ocupar o cargo; circunstância que, a teor da Jurisprudência desta Corte Superior, faz surgir o direito subjetivo do candidato à nomeação. 2. O reexame vedado em sede de Recurso Especial, nos moldes da Súmula 7/STJ, cinge-se à existência ou correção dos fatos delimitados na sentença e no acórdão recorrido; a atribuição de nova qualificação jurídica a um fato é perfeitamente possível ao STJ,pois está adstrita ao debate de matéria de direito (AgRg no EREsp.134.108/DF, Corte Especial, Rel. Min. EDUARDO RIBEIRO, DJU16.08.1999). Agravo Regimental desprovido. (AgRg no REsp 1124373/RJ. Rel. Min. Napoleão Nunes Maia Filho. 5a Turma. Julgado em 21/06/2011. DJe 01/07/2011)."

Do ponto de vista da terceirização, tem-se de forma clara que, tal qual vem sendo utilizada pelas instituições financeiras públicas no Brasil, tem se apresentado como instrumento impeditivo do direito constitucional do ingresso em concurso público, a partir do momento em que contrata funcionários terceirizados, os quais irão suprir as vagas das quais necessita a instituição. Enquanto isso, milhares de cidadãos dedicam suas vidas à aprovação em tais concursos quando se mantém em uma mera expectativa de direito, frustrada diante de contratações fraudulentas de empregados terceirizados para exercerem as funções típicas de um bancário, o que é vedado pela legislação aplicável, conforme explanado acima.

\section{CONSIDERAÇÕES FINAIS}

O ingresso no serviço público mediante concurso é uma garantia constitucional galgada pela Constituição de 1988, permitindo a todos os cidadãos a possibilidade de adquirir cargos ou funções públicas e a tão almejada estabilidade.

O fato é que, ao longo dos anos, o anseio por esta área profissional cresceu de forma, no mínimo, instigante, fazendo com que muitas pessoas abandonassem seus empregos ou programassem um período de suas vidas para se dedicar ao estudo de conteúdos lançados em seus devidos editais, gerando na população um senso de meritocracia onde todos podem alcançar tal objetivo, desde que aprovados no referido certame.

Com o tempo foram criadas novas formas de editais, as quais não mais garantiriam ao "concurseiro" que a mera aprovação seria suficiente para a sua convocação, surgindo a figura do cadastro de reserva, de forma que o candidato poderá se classificar, ou seja, atingir a pontuação desejada, mas não ser convocado. Assim, aquilo que seria um direito líquido e certo se tornou uma mera expectativa de direito, sob a batuta do poder discricionário da administração pública.

O novo cenário, conforme demonstraram os dados trazidos a este estudo, revelam que a questão não é apenas o cadastro de reserva, mas os editais lançados sem observância sequer 
dos prazos prescricionais que ao menos garantiam aos classificados uma expectativa de serem convocados.

Não obstante, também restou demonstrado que Ações Civis Públicas, bem como individuais, tem sido propostas com o fito de coibir ou represar tais condutas, e o Judiciário, igualmente, vem se pronunciando, em sua maioria, por meio das jurisprudências no sentido de repudiar tais estratégias puramente de mercado.

De outro norte, no que pertine à terceirização, tem-se que a falta da legislação que cuide pormenorizadamente do assunto acarreta uma grande utilização da terceirização em sua forma ilícita, ou seja, diante vazio existente ente um instituto moderno e a lacuna da lei, muitos se aproveitam para contratar trabalhadores ao alvedrio da lei, violando os princípios basilares do Direito do Trabalho, devidamente amparados pela Carta Magna, como o princípio da dignidade da pessoa humana e irrenunciabilidade salarial.

Não são necessárias muitas divagações para concluir que os empregados terceirizados contratados para trabalhar em bancos públicos de forma ilícita exercem suas atividades com cargas horárias mínimas de 44 horas semanais, podendo chegar a 54 horas, quando a CLT determina uma jornada especial para o bancário de 30 horas semanais.

Ademais, a remuneração e os direitos decorrentes da função de uma bancário nem de longe alcançam o que percebe um empregado terceirizado, violando o princípio da isonomia salarial.

Não obstante o esforço perpetrado pelo TST ao editar a Súmula $n^{\circ} 331$, este não tem se apresentado suficiente, vez que as grandes instituições bancárias, inclusive públicas, têm se insurgindo contra tal, mascarando os contratos de trabalho e utilizando-se da intermediação de mão-de-obra.

Com o fito de acompanhar a evolução da terceirização e amenizar os efeitos de uma grande lacuna da lei, novas teorias vão emergindo, como a subordinação estrutural, na tentativa de driblar as empreitadas das empresas rumo à exploração do trabalhador.

No silêncio da lei, a doutrina e a jurisprudência se sensibilizam, de modo a promoverem a aplicação de mecanismos que viabilizem o uso da mão-de-obra terceirizada. Tais mecanismos surgem como forma de, repita-se, viabilizar a prática de terceirização trabalhista nas empresas, principalmente nas instituições bancárias públicas do Brasil.

Os mecanismos, tal como foram concebidos, não buscam sobrepor o trabalhador terceirizado ao empregador ou, ainda, aos demais empregados protegidos pela CLT. Em última análise, tem por objetivo assegurar os princípios constitucionais de não-discriminação, dignidade da pessoa humana e valorização do trabalho. 
Tal entendimento se perfaz em razão da impossibilidade de sujeitar o trabalhador, seja de empresa pública ou privada, a situações laborais vexativas ou indignas, negando-lhe o cumprimento de seus direitos em detrimento do lucro exacerbado.

Verifica-se, pois, que a terceirização de uma forma geral, utilizada como técnica de mercado para potencializar as atividades nucleares da empresa não compromete o ingresso de candidatos no serviço público bancário, porém a realidade brasileira não demonstra o mesmo, já que tal técnica vem sendo utilizada com o crasso intuito de não só flexibilizar o trabalho, bem como precarizá-lo de tal forma que se torne desumano a manutenção de tal emprego.

Por fim, se torna imprescindível a adoção de medidas urgentes aptas a impedir que os bancos públicos, no caso deste trabalho, o Banco do Brasil S/A, utilizado apenas como unidade de análise, lancem editais de forma desenfreadas, violando até a expectativa de direito do candidato quando, ao que se parece, a figura do cadastro de reserva sequer deveria existir, vez que a abertura de um certame deveria ser condicionada à existência de vagas, cabendo à Administração utilizá-las discricionariamente dentro do prazo prescricional.

Quanto à terceirização, tal instrumento está longe de ser utilizado dentro dos limites constitucionais da isonomia, do valor social do trabalho e da dignidade da pessoa humana, enquanto não existir uma norma clara, objetiva, com sanções eficazes e efetivas para coibir práticas tão traiçoeiras que só são benéficas às empresas que delas se beneficiam para lucrar exacerbadamente às custas de mãos-de-obras especializadas e baratas e frustrar candidatos que passam anos estudando para o ingresso no serviço público.

Conclui-se, portanto que a utilização do cadastro de reserva e abertura de editais na vigência de outro e a prática da terceirização sem expressa definição das funções, carga horário e remuneração não podem ser consideradas como atividade-meio e, por conseguinte, impedem que novos candidatos classificados sejam efetivamente convocados.

\section{REFERÊNCIAS}

BARROS, Alice Monteiro de. Curso de Direito de Trabalho. 4.ed. São Paulo: LTr, 2008.

BRASIL, Pregão Eletrônico 2012/20382(9600) Gerência de Planejamento, Modelagem e Compras. Brasilia (DF). Diário Oficial [da] República Federativa do Brasil,

Brasília, DF, 10 out. 2012. Disponível em: https://www.jusbrasil.com.br/diarios/DOU/2012>. Acesso em: 03 mar. 2015

BRASIL, Pregão Eletrônico 2013/5317(9600) Gerência de Compras, Administração de Contratos, Pagamentos e Patrimônio. Brasilia (DF). Diário Oficial [da] República Federativa do Brasil, Brasília, DF, 31 jul. 2013. Disponível em: https://www.jusbrasil.com.br/diarios/DOU/2013/>. Acesso em: 03 mar. 2015 


\section{Constituição (1988). Constituição da República Federativa do Brasil de 1988.}

Brasília: Senado Federal: Subsecretaria de Edições Técnicas, 2009.

CLT (1943). Consolidação das Leis do Trabalho. 18 edição. Brasília: Senado

Federal: Vade Mecum. Editora saraiva, 2014.

. TRT, Recurso Ordinário $n^{\circ} 1880 / 94,2^{\text {a }}$ Vara do Trabalho, Tangará da Serra, MT,

19 de dezembro de 1994.2 Disponível em:

<http://aplicacao.tst.jus.br/consultaunificada2/jurisSearch.>. Acesso em: 05 nov. 2008.

. TRT, Recurso Ordinário $\mathrm{n}^{\mathrm{o}}$ 0000538-23.2014.5.10.0022, TRT da $10^{\mathrm{a}}$ região, TO/DF, 23 de fevereiro de 2014. Disponível em: <http://aplicacao.trt.jus.br/consultaunificada2/jurisSearch.>. Acesso em: 17 jul. 2015.

TRT, AgRg no REsp 1124373, TRT da $1^{\mathrm{a}}$ região, RJ, 21 de junho de 2011. Disponível em: <http://aplicacao.trt.jus.br/consultaunificada2/jurisSearch.>. Acesso em: 17 jul. 2015.

CATHARINO, Patrícia. As Instituições Financeiras e a Terceirazação: A reestruturação dos bancos no Brasil e no mundo, como ela se relaciona com a terceirização como froma de gestão e suas implicações como o direito do trabalho. 1.ed. São Paulo: Texonovo, 2005.

DELGADO, Maurício Godinho. Curso de Direito do Trabalho. $2^{\text {a }}$ ed. São Paulo: LTr.

DINIZ, José Janguiê Bezerra. A Terceirização e o Direito do Trabalho. 2.ed. São Paulo: Saraiva, 2002. 